\title{
Dexamethasone is cost-effective alternative to ondansetron in preventing Post-Operative Nausea and Vomiting
}

\author{
Muhammad Sazzad Hossain 1 , Md. Afzalur Rahman ${ }^{2}, \quad$ Mamunur Rashid ${ }^{3}, \quad$ Mahiuddin Alamgir ${ }^{4}$, \\ Md. Waliullah', Anisur Rahman Babu ${ }^{6}$, Devashis Saha ${ }^{7}$
}

\begin{abstract}
Background: Postoperative nausea and vomiting (PONV) is a common complication of anesthesia and surgery. Numerous anti-emetics have been studied to prevent and treat PONV.

Methods: This study evaluated the antiemetic efficacy, cost-effectiveness and clinical utility of prophylactic dexamethasone and ondansetron compared with placebo in prevention of postoperative nausea and vomiting after ENT surgery in 90 patients.
\end{abstract}

Results: The incidence of PONV was significantly greater in placebo group than dexamethasone group and ondansetron group $(p<0.05)$. The incidence in the dexamethasone group $10 \%$ and ondansetron group $26.66 \%$ were comparable $p>0.05$. The incidence of early $(0-6 \mathrm{~h})$ PONV was significantly lower in dexamethasone group and ondansetron group than the placebo group $(p<0.05)$. The early incidence was comparable in the dexamethasone $(10 \%)$ and ondansetrone $(13.33 \%)$ group $(p>0.05)$. The incidence of PONV in the late postoperative period (6-24 h) was significantly lower in the dexamethasone group $(3.33 \%)$ than the ondansetron group $(23.33 \%) \mathrm{P}<0.05$.

Conclusion: Both dexamethasone and ondansetron were more effective than placebo in preventing postoperative nausea and vomiting after ENT surgery but dexamethasone was more effective, less expensive and safer than ondansetron, therefore, it may be better substitute for ondansetron.

Keywords: Dexamethasone, Ondansetron, Nausea, Vomiting.

1.Dr. Muhammad Sazzad Hossain

MBBS PhD FCPS (anes)

Associate Professor and HOD

Department of Anesthesiology

National Institute of ENT. Tejgaon, Dhaka.

2. Dr. Md. Afzalur Rahman. FCPS (anes)

Junior consultant, department of anesthesiology. NIENT.

3.Dr. Mamunur Rashid. DA

Junior Consultant, department of anesthesiology. NIENT.

4. Dr. Mahiuddin Alamgir. DA
Research officer, department of anesthesiology. NIENT.

5. Dr. Md. Waliullah. MCPS DA

Medical officer, department of anesthesiology. NIENT

6.Dr.Anisur Rahman Babu. DA

Medical officer, department of anesthesiology. NIENT.

7.Dr. Devashis Saha. MBBS

Research officer, department of anesthesiology. NIENT 
Address of correspondence:

Dr. Muhammad Sazzad Hossain

MBBS PhD FCPS (anes)

Associate Professor and HOD

Department of Anesthesiology

National Institute of ENT. Tejgaon, Dhaka.

Mobile: +8801779849059

E mail: sazzadicu786@yahoo.com

\section{Introduction}

Postoperative nausea and vomiting (PONV) is defined as the occurrence of nausea and vomiting in patient after surgical operation, starting from post-anesthesia care unit (PACU) to the early hours of transferring the patient to the ward, without any clear reasons like hypotension ${ }^{1}$. Postoperative nausea and vomiting rate has been reported to vary $(20 \%$ $30 \%$ ) in various surgical operations and in different methods of anesthesia and constitutes the second most common complaint reported ${ }^{2}$. The PONV incidence rate in patients of high risk groups could be as high as $70 \%-80 \%{ }^{3}$. Additionally, children are not exemptible from PONV. The incidence rate for children above the age of 3 exceeds $40 \%$. It is not until they have reached puberty does the incidence rate begin to decline. PONV is highly troubling: it not only results in delayed discharge from the hospital, leading to lavishing medical resources, but also reduces patient satisfaction.

Traditional preventive treatment of PONV includes: serotonin type 3 receptor antagonist (ondansetron, dolasetron and granisetron), dopamine type 2 receptor antagonist (metoclopramide and droperidol), muscarinic cholinergic type 1 receptor antagonist (scopolamine), histamine type 1 receptor antagonist ( promethazine and prochlorperazine). Ondansetron has a number of side effects including hypersensitivity reaction, headache, lightheadedness, dizziness, obstruction of intravenous line, increase of liver transaminases level, feelings of heat in the epigastrium, constipation and cardiac dysrhythmia. The clinical dose of the drug (4$8 \mathrm{mg}$ ) usually does not have any side effect ${ }^{1}$.

Since the mid 1980s, studies have shown that dexamethasone can reduce vomiting in patients after chemotherapy ${ }^{4,5}$. Subsequent studies have also found that dexamethasone can effectively prevent PONV induced by epidural morphine used to reduce postoperative pain ${ }^{6,7}$. A decade ago, results from meta-analysis have further suggested that the preventive effect of dexamethasone against PONV is similar to ondansetron ${ }^{8}$. The mechanism of action of dexamethasone in PONV prevention is still not fully understood. Dexamethasone is a synthetic form of adrenocorticoid and acts mainly as a glucocorticoid receptor with almost no mineralocorticoid receptor function ${ }^{9}$. Some glucocorticoid receptors are related to the physiological conduction pathway for vomiting. The glucocorticoid receptors exist in the part of brain stem where the nucleus of tractus solitarious and area postrema reside. Other possible explanations for dexamethasone preventing PONV include central inhibition of prostaglandin synthesis, reduction of central serotonin activity and change of permeability of blood-brain barrier to plasma proteins ${ }^{10}$. Beyond these possible explanations for dexamethasone preventing PONV, the anti-inflammatory effect of dexamethasone is even stronger. Dexamethasone can effectively reduce local inflammatory reaction after surgery; this may reduce the inflammation triggered by afferent stimulation of parasympathetic nervous system to the vomiting center, thereby reducing PONV. Additionally, dexamethasone increases synthesis of endorphin in the body, uplifting moods and appetite ${ }^{9}$. The recommended intravenous dose of dexamethasone for prevention of PONV in adult is $2.5 \mathrm{mg}$ to $10 \mathrm{mg}$ 11 and its recommended dose for children is $0.15-1 \mathrm{mg}$ per $\mathrm{kg}$ body weight ${ }^{12}$. The timing of administration of dexamethasone is crucial for preventing PONV. Intravenous dexamethasone generally requires longer period of time to take effect and a time lag of 12-24 hours to achieve 
the maximal result ${ }^{9}$ and its physiological effect in the body can remain for 36-72 hours ${ }^{9}$.

In terms of these pharmacological properties, the characteristic of dexamethasone is clearly a drug with the slow onset time and long duration of action. Studies have showed that the antiemetic effect of dexamethasone begins approximately 2 hours after intravenous injection ${ }^{13}$.

Because of its low cost and safety in use, dexamethasone may be the first drug of choice in preventing PONV ${ }^{14,15}$. In our study, we aimed to compare the efficacy, safety, costeffectiveness and clinical utility of prophylactic dexamethasone, ondansetron and placebo in postoperative nausea and vomiting after ENT surgery.

\section{Methods}

This was a randomized double blind study conducted at National Institute of ENT (NIENT) Dhaka, during the period of December2017 to January 2018. After having obtained written informed consent from all 90 patients of either sex, aged between 20 and 50 years, belonging to American Society of Anesthesiologists (ASA) physical status class $\mathrm{I}$ and II, undergoing elective surgery likely to last between 30 and 90 minutes under general anesthesia with endotracheal intubation, were included in this study. Pre-anesthetic evaluation was done in all patients. The patients enrolled were randomly assigned to one of the three equal groups of 30 patients each.

Dexamethasone group: $5 \mathrm{mg}$ dexamethasone dissolved in $5 \mathrm{ml}$ normal saline was given intravenously after induction of anesthesia.

Ondansetron group: $4 \mathrm{mg}$ ondansetron dissolved in $5 \mathrm{ml}$ normal saline was given intravenously after induction of anesthesia.

Placebo group: $5 \mathrm{ml}$ normal saline intravenously given after induction of anesthesia.
Routine pre-anesthesia evaluation was carried out in all patients a day prior to the scheduled procedure.

On arrival of the patient in the operating room, non- invasive blood pressure, electrocardiogram and pulse oximeter were attached. Base line values for pulse rate, Blood pressure and arterial oxygen saturation were measured and recorded. Non-invasive blood pressure was recorded at 5 minutes interval throughout the procedure. The patients were kept nil per oral from the midnight before surgery. After securing the intravenous access with $20 \mathrm{G}$ cannula, infusion started with Ringers Lactate $1.5 \mathrm{ml}$ per $\mathrm{kg}$ per hour then premedication was done with intravenous fentanyl $2 \mathrm{mg}$ per $\mathrm{kg}$ body weight. Induction of anesthesia was done with a titrated dose of intravenous propofol after 3-5 minutes pre oxygenation. Vecuronium $0.1 \mathrm{mg} / \mathrm{kg}$ body weight was given for muscle relaxation. After 3 minutes of assisted ventilation the trachea was intubated with a single use high volume low pressure cuffed polyvinyl chloride endotracheal tube 7.5 and $7.0 \mathrm{~mm}$ internal diameter (ID) for male and female patients respectively. Position of ETT was confirmed. General anesthesia was maintained as standard procedure with halothane, nitrous oxide, oxygen, vecuronium and fentanyl as required.

At the end of surgery, $100 \%$ oxygen was administered, residual neuromuscular block was antagonized with neostigmine $0.05 \mathrm{mg} / \mathrm{kg}$ and atropine $0.02 \mathrm{mg} / \mathrm{kg}$. Oral suction was done just before extubation. The trachea was extubated after deflating the cuff when the patient was fully awake. Assessment of patients for postoperative nausea and vomiting was done according to questionnaire at 0-6 hours and 6-24 hours.

\section{Questionnaire of postoperative nausea and vomiting.}

$0=$ No nausea or vomiting.

$1=$ Nausea but no vomiting

$2=$ Vomiting once in 30 minutes or more. 
$3=$ Persistent nausea $(>30 \mathrm{~min})$ or two or more vomits in 30 minutes.

Statistical analysis:

Data was collected and recorded as per questionnaire and analyzed statistically. Quantitative variables were summarized as mean \pm standard deviation. One-way analysis of variance (ANOVA) was used to compare means for patient characteristics across treatment groups. Chi square test was done for incidence and severity of postoperative nausea and vomiting. The positive number needed to prevent (NNTP) PONV (which indicates how many patients had to be exposed to dexamethasone or ondansetrone to prevent PONV) was calculated as the reciprocal of the absolute risk reduction of the incidence of PONV from basal (placebo) incidence for patients who received dexamethasone or ondansetron. The cost to benefit a patient was calculated as the drug cost per patient times the NNTP for dexamethasone or ondansetron. $\mathrm{P}<0.05$ was considered statistically significant.

\section{Results}

Patients demographic and clinical characteristics such as age, sex, body weight, physical status, duration of surgery were similar in all three groups Table I. The incidence of PONV was significantly greater in placebo group than dexamethasone group and ondansetron group $(p<0.05)$ Table II. The incidence in the dexamethasone group $10 \%$ and ondansetron group $26.66 \%$ were comparable $p>0.05$. The incidence of early $(0-6 \quad h)$ PONV was significantly lower in dexamethasone group and ondansetron group than the placebo group ( $p$ $<0.05$ ). The early incidence was comparable in the dexamethasone $(10 \%)$ and ondansetrone $(13.33 \%)$ group $(p>0.05)$. The incidence of PONV in the late postoperative period (6-24 h) was significantly lower in the dexamethasone group $(3.33 \%)$ than the ondansetron group $(23.33 \%) \quad P<0.05$. The severity of PONV was significantly lower in the dexamethasone and ondansetrone group compared with placebo group $p<0.05$ Table III. Headache was seen in four patients in ondansetron group. No patients had any evidence of hyperglycemia, delayed wound healing or any antiemetic related side effects except headache in any groups of patients.

The positive NNTP was comparable in the dexamethasone (NNTP=1.66) and ondansetron (NNTP=2.30) groups. The drug cost per patient was 15 taka in dexamethasone group 30 taka in the ondansetron group. The cost to benefit per patient ( NNTP times the drug cost) was 2.77 times higher in the ondansetrone group than in dexamethasone group.

Table I: Patients demographic and clinical characteristics

\begin{tabular}{|c|c|c|c|c|}
\hline & Dexamethasone & Ondansetron & Placebo group & $p$ value \\
\hline & group $(n=30)$ & group $(n=30)$ & (30) & \\
\hline Age (years) & $44.21 \pm 6.87$ & $46.04 \pm 7.56$ & $45.94 \pm 6.43$ & $p>0.05$ \\
\hline $\operatorname{Sex}(M / F)$ & $18 / 12$ & $20 / 10$ & $21 / 9$ & \\
\hline Body weight (kg) & $65.02 \pm 4.81$ & $63.86 \pm 6.04$ & $62.91 \pm 4.97$ & $p>0.05$ \\
\hline ASA $1 / I I$ & $27 / 3$ & $28 / 2$ & $28 / 2$ & \\
\hline Duration of surgery (min) & $84.64 \pm 12.32$ & $81.72 \pm 13.14$ & $85.83 \pm 10.54$ & $p>0.05$ \\
\hline Base line pulse rate & $78.6 \pm 8.2$ & $81.1 \pm 6.9$ & $79.8 \pm 7.8$ & $p>0.05$ \\
\hline Base line MAP (mmHg) & $88.4 \pm 7.6$ & $91.6 \pm 6.9$ & $89.9 \pm 8.3$ & $p>0.05$ \\
\hline
\end{tabular}


Types of operation
1. Tympanoplasty
12
10
13
2. Septoplasty
7
8
6
3. Tonsillectomy
8
9
9
4. Hemithyroidectomy
3
3
2

Table II: PONV incidence

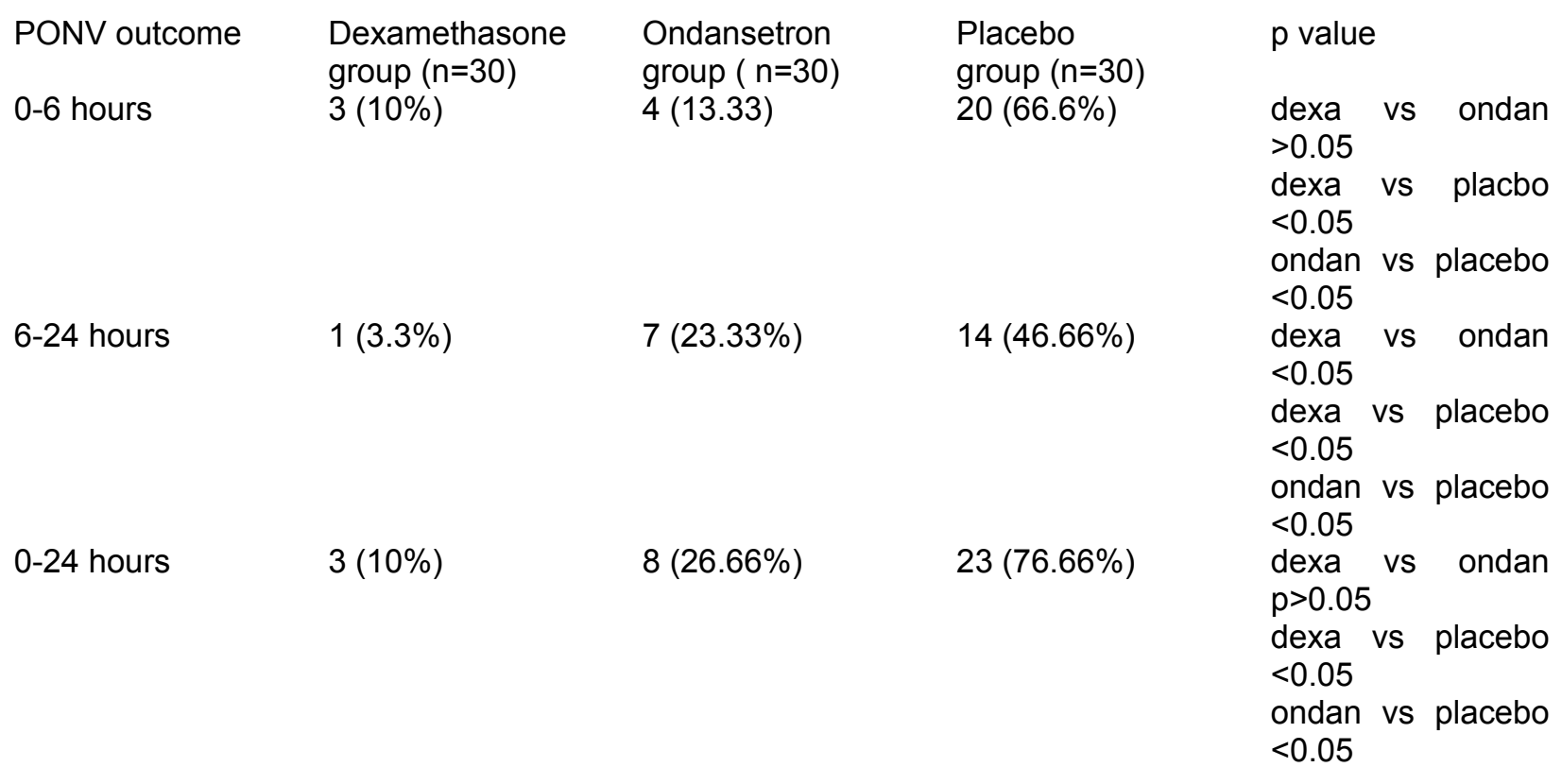

Table III: Severity of PONV

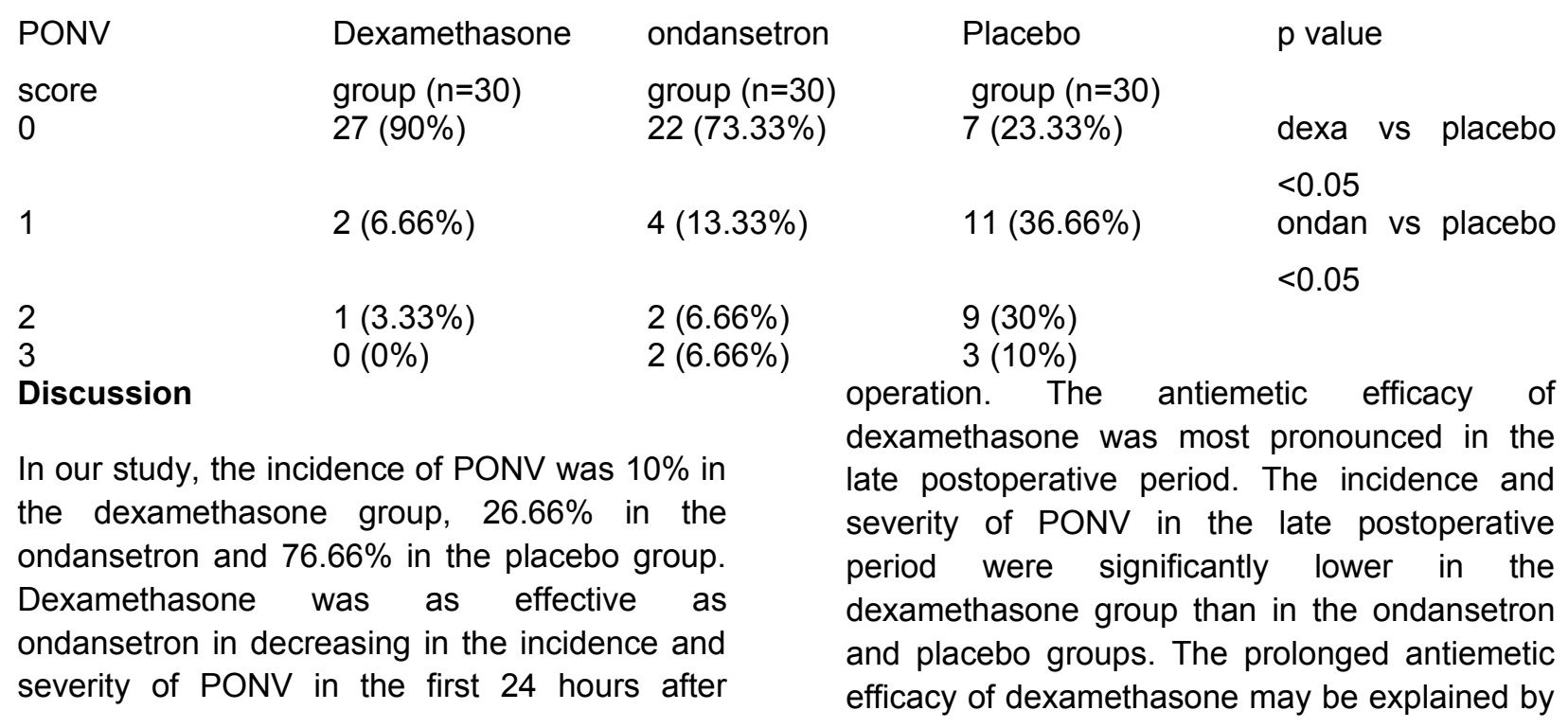


its prolonged biological half-life (36-72 hours). Similar findings have been reported in patients undergoing ambulatory surgery ${ }^{16}$. Dexamethasone has been shown to provide greater protection from delayed chemotherapyinduced nausea and vomiting compared with ondansetron and granisetron ${ }^{17}$.

In this study, the groups were comparable with respect to patient characteristics, surgical procedure, anesthetics administered and intravenous fluids used in the perioperative period. Therefore, the difference in the incidence and severity of PONV and true and therapeutic outcome measures among the groups in this study can be attributed to the study anti-emetics were administered. We included a placebo group to allow us to calculate the absolute reduction in the risk of PONV and thereby the NNTP. The NNTP indicates how many patients need to be exposed to the treatment in order to prevent PONV in one of them.

Previous studies have shown that compared to distilled water, intravenous dexamethasone significantly reduced the rate and intensity of PONV ${ }^{18}$. Erhan et al. conducted a comparative study on ondansetron, granisetron and dexamethasone effects given before induction of anesthesia to prevent PONV in laparoscopic cholecystectomy. They showed that compared to placebo all the three drugs in similar manner significantly reduced the incidence rate of PONV ${ }^{19}$. Lopez-Olando et al. reported that dexamethasone was as effective as ondansetron in reducing nausea and vomiting induced by chemotherapy ${ }^{20}$. Gupta also concluded that intravenous dexamethasone and ondansetron had a similar effect on PONV prevention. Another study showed that dexamethasone was a little more effective than ondansetron in preventing post-tonsillectomy PONV ${ }^{21}$.

The timing of prophylactic antiemetic administration is important. We administered the drugs at the beginning of the procedure. It has been confirmed recently that dexamethasone is more effective when administered at induction than when given at the end of anesthesia ${ }^{22}$. Though it has been suggested that ondansetron given at the end of surgery will reduce antiemetic requirements more effectively in the postoperative period ${ }^{23}$, in short surgical procedures like 30-90 minutes duration of our operations, administering ondansetron at the beginning or the end of surgery did not affect the outcome ${ }^{24}$.

\section{Conclusion}

In this study, we found that both dexamethasone and ondansetron were more effective than placebo in preventing postoperative nausea and vomiting after ENT surgery but dexamethasone was more effective, less expensive and safer than ondansetron, therefore, it may be better substitute for ondansetron.

\section{References}

1. Miller Rd, Eriksson LI, Fleisher LA, WeinerKronish JP, Young WI. Millers Anesthesia. $6^{\text {th }}$ ed. USA: Churchill Livingstone ; 2009. p. 231733

2. Jabalameli M, Rouholamin S, Gourtanian F. A comparison of the effects of fentanyl and remifentanyl on nausea, vomiting and pain after cesarean-section.

Iran J med Sci. 2011;36:183-7

3. Watcha MF, White PF. Postoperative nausea and vomiting. Its etiology, treatment and prevention. Anesthesiology 1992; 77: 162-84.

4. Italian Group for Antiemetic Research. Dexamethasone, granisetrone or both for the prevention of nausea and vomiting during chemotherapy for cancer. N Engl J Med 1995;332:1-5.

5. Italian Group for Antiemetic Research. Double-blind dose-finding study of four intravenous dose of dexamethasone in the prevention of cisplatin-induced acute emesis.

J Clin Oncol. 1998;16:2937-42. 
6. Wang JJ, Ho ST, Liu HS, Ho Cm. Prophylactic antiemetic effect of dexamethasone in women undergoing ambulatory laparoscopic surgery. Br J Anesth 2000; 84:459-62.

7. Wang JJ, Ho ST. Liu YH, Ho CM, Liu K, C Hia $Y Y$. Dexamethasone decreases epidural morphine-related nausea and vomiting. Anesth Analg; 1999: 89:117-20.

8. Henzi I, Walder B, Tramer MR. Dexamethasone for the prevention of postoperative nausea and vomiting: a quantitative systemic review. Anesth Analg 2000; 90: 18694.

9. Holte $\mathrm{K}$, Kehlet $\mathrm{H}$. Perioperative single dose glucocorticoid administration: pathophysiologic effects and clinical applications. J Am Coll Surg 2002;195:694-712.

10. Ho CM, Ho ST, Wang JJ, TsaiSk, Chai CY. Dexamethasone has a central antiemetic mechanism in decerebrated cats. Anes Analg 2004;99:734-9.

11. Wang JJ, Ho ST, Lee SC, Liu YC, Ho CM. The use of dexamethasone for preventing postoperative nausea and vomiting in females undergoing thyroidectomy: a dose-ranging study. Anesth Analg 2000; 91: 1404-7.

12. Steward DL, Welge JA, Myer CM. Do steroids reduce morbidity of tonsillectomy ? Meta-analysis of randomized trials. Laryngoscope 2001; 111: 1712-8.

13. Thangaswamy $C R$, Rewary $V$, Trikha $A$, Dehran M, Chandralekha. Dexamethasone before total laparoscopic hysterectomy: a randomized controlled dose response study.

J Anesth 2010; 24: 24-30.

14. Karanicolas PJ, Smith SE, Kanbur B, Davies E, Guyatt GH. The impact of prophylactic dexamethasone on nausea and vomiting after laparoscopic cholecystectomy: a systemic review and meta-analysis. Ann Surg 2008;248: 751-62.
15. Apfel CC, korttila $\mathrm{K}$, Abdalla $\mathrm{M}$, Kerger $\mathrm{H}$, Turan A, Vedder I, et al. A factorial trial of six interventions for the prevention of postoperative nausea and vomiting.

N Engl J Med 2004; 350: 2441-51.

16. Wang JJ,Ho ST, Liu HS, Ho CM. Prophylactic antiemetic effect of dexamethasone in women undergoing ambulatory laparoscopic surgery, Br J Anesth2000; 84: 459-62.

17. The Italian Group for Antiemetic Research: Dexamethasone, granisetron or both for the prevention of nausea and vomiting during chemotherapy for cancer.

N Engl J Med 1995; 332:1-5.

18. Nesek- Adam V, Grizelj-Stojcic E, Rasic Z, Cala Z, Mrsic V, Smiljanic A. Comparison of dexamethasone, metoclopramide and their combination in the prevention of postoperative nausea and vomiting. Surg Endosc. 2007;21:607-12.

19. Erhan $\mathrm{Y}$, Erhan E, Aydede H, Yumus O, Yentur A. Ondansetron, granisetron and dexamethasone compared for prevention of postoperative nausea and vomiting in patient undergoing laparoscopic cholecystectomy: A randomized placebo controlled study.

Surg Endosc 2008; 22:1487-92.

20. Lopez-Olando L, carrascosa F, Pueyo FJ, Monedero P, Busto N, Saez A. Combination of ondansetron and dexamethasone in the prophylaxis of postoperative nausea and vomiting.

Br J Anesth. 1996; 76: 835-40.

21. Bolton CM, Myles PS, Nolan T, Sterne JA. Prophylaxis of postoperative vomiting in children undergoing tonsillectomy: a systemic review and meta-analysis. Br J Anesth. 2006;97:593-604.

22. Wang JJ, Ho ST, Tzeng JI, Tang CS. The effect of timing of dexamethasone administration 
on its efficacy as a prophylactic antiemetic for postoperative nausea and vomiting.

Anes Analg 2000;91:136-9.

23. Sun R, Klein KW, White PF. The effect of timing of ondansetron administration in outpatients undergoing otolaryngologic surgery. Anesth Analg 1997; 84: 331-36.

24. Madan R, Perumal T, Kathervel S, et al. The effect of timing of prophylactic ondansetron administration on postoperative emesis following pedeatric strabismus surgery. Anesth Intensive Care 2000;28: 27-30 